San Jose State University

SJSU ScholarWorks

Master's Projects

Master's Theses and Graduate Research

$5-14-1998$

\title{
Are We asking the Right Questions? An Evaluation of Client Reportability to Medical Providers Concerning Concurrent Use of Alternative Therapies
}

Nektarios Butterfield

San Jose State University

Follow this and additional works at: https://scholarworks.sjsu.edu/etd_projects

Part of the Other Nursing Commons

\section{Recommended Citation}

Butterfield, Nektarios, "Are We asking the Right Questions? An Evaluation of Client Reportability to Medical Providers Concerning Concurrent Use of Alternative Therapies" (1998). Master's Projects. 839. DOI: https://doi.org/10.31979/etd.qvjq-d8xe

https://scholarworks.sjsu.edu/etd_projects/839

This Master's Project is brought to you for free and open access by the Master's Theses and Graduate Research at SJSU ScholarWorks. It has been accepted for inclusion in Master's Projects by an authorized administrator of SJSU ScholarWorks. For more information, please contact scholarworks@sjsu.edu. 
Are We Asking the Right Questions?

An Evaluation of Client Reportability

to Medical Providers

Concerning Concurrent Use of Alternative Therapies

\author{
Presented to \\ The Faculty of the Department of Nursing \\ San Jose State University \\ In Partial Fulfillment \\ of the Requirements for the Degree \\ Masters of Nursing
}

By

Nektarios Butterfield

May 14,1998 


\begin{abstract}
The use of alternative therapies in the United States is becoming more and more prevalent. One out of three Americans use alternative therapies and the failure to report the use of alternative therapies could affect the client's health. The purpose of this study was to explore the extent to which clients use and report their use of alternative therapies to their medical care provider, as well as identifying barriers to reporting.

A sample $(\underline{N}=50)$ was selected randomly from a phone book. Of those $34(68 \%)$ who used alternative therapies, $64 \%(n=32)$ reported use of alternative theraples while receiving medical care within the last year. Only $18(56 \%)$ of those using alternative therapies reported the use to their medical provider. Although these flgures are higher than national surveys, clients continue to perceive barriers to discussing the use of alternative therapies with their medical providers. This study found that those who perceived no barriers were more likely to discuss specific details regarding their use of alternative therapies to their medical care providers. Recommendations are made for incorporating information about reporting alternative therapies into routine assessments of all clients.
\end{abstract}




\section{Background}

There are an estimated $\mathbf{4 2 5}$ million client visits to alternative therapists annually. This far exceeds the 388 million visits to primary care providers by adults in the United States in the same year. These statistics were included in a landmark study performed by Calkins, Delbanco, Eisenberg, Foster, Kessler, and Norlock in 1993 in which one out of three clients surveyed used alternative therapies for serious medical conditions. It was found that the majority of those respondents (72\%) did not notify their medical provider. ${ }^{1}$ Earlier studies by Kleinman and colleagues in 1978 informed the medical community of the prevalence of alternative therapies and the low incidence of client reporting. ${ }^{1}$

Sutherland and Verhoef (1995) described alternative medicine as any health practice which was viewed as unconventional or did not conform to standards set by the medical community. Since the use of the word medicine is commonly associated with medical care, the term alternative therapy will be used in this article instead of alternative medicine to avoid confusion. Alternative therapies have been associated with a "holistic" (p.1066) approach which focuses on natural processes of restoring and maintaining a normal state of health. This approach contrasts to the allopathic, or the medical, approach which focuses mostly on the diagnoses and treatment of disease and pathology. 2

Alternative therapies are also referred to as complementary, unorthodox, or unconventional and are becoming more prevalent in the United States because of consumer demand. However, alternative therapies have not become mainstream in America mostly because there continues to be a lack of data and research to support 
their use. 3

The purpose of this study was to explore in a quantitative manner the extent to which clients use and report their use of alternative therapies to their medical care provider. The perceived barriers which clients felt prevented them from reporting the use of alternative therapies was also explored in this study so that the information gained could be applied to practice. Since nurse practitioners (NPS) are considered primary medical care providers, and are perceived by the public as such, this study did not propose to distinguish between nurse practitioners and medical doctors when conducting this research.

Why is discussing a client's use of alternative therapies important? Slagle (1996) suggested there are physiological as well as ethical and legal implications regarding the Nurse Practitioner's (NP's) knowledge of alternative therapy use. Risks of not having accurate information include: (a) toxicity from improper use of alternative substances, (b) possible malefic interactions with medical regimens, (c) decreased efficacy of medical care, and (d) the possibility that effective medical care may be delayed. The extent to which clients report their use of alternative therapies may also reflect the level of trust and communication the client has with the NP. The advantage of a client revealing the use of alternative therapies is that the health care provider can better document and monitor the client's progress while demonstrating concern by educating and counseling the client concerning any potential problems. 4

Studies done by Laing and Montbriand (1991) suggested that clients who used alternative therapies for serious medical conditions did so in an effort to regain control over their own health and to relieve anxiety. These researchers discovered through interviews that clients encountered cold resistance when discussing 
alternative therapies with their medical providers. These authors also described consumer dissatisfaction with traditional health care systems because of the inability to relieve symptoms associated with cancer and other chronic illnesses. 5

The psychological benefit that clients reported regarding use of alternative therapies is being documented more thoroughly. Research performed by Cronsberry (1996) found that nurses tend to be more knowledgeable concerning alternative therapies used by clients along with traditional cancer therapies. This open approach appeared to be effective both physically and psychologically for the client.

Conventional cancer treatments contribute little to a client's sense of control since the process was often destructive and the side effects were immense. 6

\section{Conceptual Framework}

Pender (1996) described the Health Promotion Model (HPM) as a framework for exploring the social and psychological factors that influence one's attitudes towards a more healthy lifestyle. One of the HPM's basic premises is that people seek to create a living environment in which they can self-actualize their own unique potential for health. The environment, one's behavior, and interpersonal factors all influence one's health promoting behaviors. Health care providers can play a major role in the interpersonal environment and can influence clients' health promoting behavior throughout their life. This model identifies cognitive and perceptual factors that are involved when attempting behaviors that promote health. 7

\section{Methods}

The survey designed by the researcher contained eight questions (See Table 1). Item 1 asked if alternative therapies were being used and what were they. Item 2 
asked if the therapies were the client's own decision or if under medical referral. Item 3 asked if the client had undergone medical treatment within the last year. Item 4 asked if this treatment by a medical provider was the same as the reason for using the alternative therapy. Items 5 and 6 asked about information revealed to the medical provider and whether the provider asked or the information was volunteered about: (a) amount, (b) frequency of use, (c) length of time therapies used, (d) specific type of herb, vitamin, or mineral, or (e) effectiveness of the alternative therapy. Item 7 asked the client to estimate a percentage of information about alternative therapy use revealed to the medical provider. Item 8 was an open ended question about what prevented the client from reporting or discussing these therapies with the medical provider.

This research used telephone interviews from January 28th to March 1st, 1998 to obtain responses to the survey. The sample was chosen by random selection from a 1997 phone book that included eight different cities in the South Bay region of Northern California. The survey consisted of eight questions and took approximately three to five minutes to complete. Eligibility was limited to persons who were 18 years of age or older and who spoke English without any apparent difficulty.

A majority of the 493 telephone calls that were made were answered by recordings (84\%) and were not called back later. Out of 80 people who answered the phone, $62.5 \%(n=50)$ agreed to participate in the survey and $35 \%(n=28)$ declined. Reasons for declining included lack of time, lack of interest, or other pressing matters. Only two respondents $(2.5 \%)$ were not eligible because of language barriers. The survey was performed between 10 a.m. and 4:30 p.m. during weekdays and did not include holidays. 


\section{Results}

\section{Alternative Therapies}

A majority of the respondents were women $(70 \%, \underline{n}=35)$ which may have reflected the time in which the survey was conducted. Specific ages and sex categories were not recorded. Among 50 participants who responded to the survey, $68 \%(n=34)$ were currently using at least one form of alternative therapy within the last year of the interview. Of the 34 subjects who used alternative therapies, the most current alternative therapies used were vitamins and herbs $(n=28)$. Chiropractic was the second most frequently used alternative therapy $(\underline{n}=9)$. Three participants stated they used acupuncture within the last year. Five people used massage therapy and two participants stated they used energy healing. Twelve respondents used more than one alternative therapy.

Out of the 34 participants who stated they were using an alternative therapy, $32(64 \%)$ were using alternative therapies while currently under medical supervision (See Table 2). The following results were computed as a percent of these 32 and do not include subjects not receiving medical care while using alternative therapies. Two (6\%) stated that the alternative therapy was being used because of medical referral, and $94 \%(n=30)$ stated that it was their own decision to use the alternative therapy. Ten $(31 \%)$ participants were using alternative therapies for the same reason they were going to a medical provider. This statistic is higher than results cited by Eisenberg and colleagues in 1993 in which $11 \%$ of respondents used alternative therapies for the same reason they were going to a medical provider. 1 A little more than half of these participants $(56 \%, \underline{n}=18)$ stated that they had revealed their use of the alternative therapies to their medical provider; however, a portion of this information 
was volunteered by the client rather than asked by the provider. For instance, $22 \%$ $(\mathrm{n}=7)$ stated that the medical provider had asked about the amount of alternative therapy being used, but $6 \%(n=2)$ volunteered this information. The provider asked about the type of herb, vitamin, or mineral being used for $9(28 \%)$ clients, and two $(6 \%)$ volunteered the information. The provider asked about the outcome or effectiveness of the alternative therapy being used in $25 \%(\underline{n}=8)$ of the clients using alternative therapies, and three $(9 \%)$ of the clients volunteered this information. However, concerning information about the number of visits or the length of time a client was using alternative therapies, only $12 \%(n=4)$ were asked and no client volunteered this information. When the client was asked to estimate a percentage of information about their use of alternative therapies which had been revealed to the medical provider, $38 \%(n=12)$ estimated $0 \%$ and $28 \%(n=9)$ said they had revealed $100 \%$ of information to the provider. Of all the responses, there were a total of 14 clients who responded that they had revealed $50 \%$ or more of the information about use of alternative theraples to their medical provider.

\section{Barriers}

Item 8 on the survey asked the clients what prevented them from reporting or discussing their use of alternative therapies with the medical care provider (See Table 3). The responses were divided into three categories: (a) no perceived barriers, (b) barriers related to the participant's perception of doctor's opinion towards and interest in alternative therapies, and (c) barriers relating to the client's perception of relevancy. Examples of responses in the no perceived barriers category included: "Nothing, I volunteered," "Nothing, When I spend alot of money, I'm going to tell the doctor everything," and "There were no barriers, my doctor is open to that sort of thing."

The category representing the participant's view or perception of the medical provider's opinion towards alternative therapies contained statements such as, "They 
are just not supportive," "M.D.'s don't believe that Chiropractic works," and "M.D.'s believe in their own technology." The responses which revealed the cllent's perception of whether the alternative therapy was relevant included responses such as "I didn't think it was important," and "I think it works so I didn't need to tell the doctor. It didn't hurt anything." The frequency or amount of medical use was categorized as perception of relevancy with one person being quoted as saying, "because I don't go to a doctor on a regular basis."

\section{Discussion}

This study demonstrated several trends when compared to a larger national study regarding the use of alternative therapies and the reporting of alternative therapies to one's medical care provider. This study found that $68 \%$ of the 50 participants used at least one form of alternative therapy. This statistic is higher than one national study cited by Eisenberg and colleagues in which approximately one in three clients (34\%) used some form of alternative therapy. 2 The reason for this present study's unusually high finding is unknown and would require more demographic statistics such as income, current trends in HMO organizations, and many other factors that could influence use of these therapies. Comparing local trends to national trends could be very useful when identifying variables that have been shown to affect attitudes towards specific health care trends. For instance, Acupuncture and Chiropractic are becoming more and more recognized by health maintenance organizations (HMOs), medical practitioners and their clients. The incorporation of these alternative therapies by HMOs may have an impact regarding their use on both local and national levels.

The fact that a large percentage of the sample $(69 \%, \underline{n}=22)$ stated that they are not going to a medical provider for the same reason they are using alternative therapies 
may suggest that the use of alternative therapies is not limited to current medical concerns. However, three participants volunteered that they were using alternative therapies and going to a medical provider concurrently for a serious and chronic health problem. This result is similar to a larger study done by Eisenberg and colleagues in 1993. Eisenberg's study demonstrated a high percentage of people (83\%) who used alternative therapies for their serious chronic illnesses also used medical care for the same reason. All respondents in Eisenberg's larger national study of over 1500 participants who used alternative therapies for cancer specifically were also undergoing medical treatment for the same condition. 1

Although the percentage of participants who revealed to their medical providers that they were using alternative therapies $(56 \%)$ was higher than figures cited in a national study (28\%) researching this subject ${ }^{1}$ (See Table 2), the extent to which clients are being asked specific information such as frequency, amounts, and outcomes is extremely deficient. There are no studies regarding the extent to which clients report their use of alternative therapies to compare with the findings found in this study.

One participant was quoted as saying. "I went to the clinic for my knee and I didn't think the herbs and vitamins I was taking had anything to do with my knee." The doses of vitamins and herbs were not explored in this case. The client did not perceive the efficacy of discussing the use of alternative therapies with the medical provider nor was the client asked by the provider if alternative therapies such as vitamins and herbs were being used. Yet, there have been documented cases in which hepatotoxicity occurred from taking 10,000 units of vitamin A per day along with alcohol use. Also, the intake of a common herb such as comfrey, which contains pyroloizidine alkaloids, has been associated with causing venocclusive diseases in humans. 8 The possible case scenario of the client with the knee injury could have 
included liver injury which may have affected blood clotting factors produced by the liver, which would be a crucial variable to a doctor who was considering knee surgery on this patient. This type of report clearly points to the importance of asking clients about their use of alternative therapies and not relying on the client's perception of relevance when reporting. This demonstrates the importance of making the medical provider aware of the use of alternative therapies. Yet when the participants in this survey did reveal the use of alternative therapies, often other specific information was neither asked for nor volunteered to the medical provider.

This study revealed that the perception of relevancy was one of the main barriers in reporting the use of alternative therapies to the medical provider. Other barriers such as a client's perception that the doctor had strong negative opinions towards alternative therapies apparently continued to exist according to this survey. Asking specific information regarding client's use of alternative theraples may serve to decrease these perceived barriers. Studies by Fletcher (1992) have shown that effective communication between patient and nurse can clarify many misconceptions and clarify treatment options for the patient. An exploration in the use of alternative therapies by the NP can aid in both a better understanding and a more effective communication between the client and the medical provider. 9

It is interesting to note that out of the 11 participants who perceived no barriers to discussing their use of alternative therapies, eight clients either reported or volunteered specific information to their medical provider including frequency of use, amounts, outcomes, and length of treatment. These eight participants felt that they had reported $100 \%$ of information concerning their use of alternative therapies. All of these participants had discussed at least two details with their medical provider regarding their use of alternative therapies such as frequency, outcomes, amounts, and length of 
use.

Limitations of this study include the small, non-random sample. The sample was limited to respondents who answered the telephone, which may cause bias from demographic variables such as culture, income, education, age, or gender. Another limitation may have been that the tool needs further use and testing for reliability and validity. Also, there may be perceived barriers of participants who respond to surveys over the phone that may not be apparent.

\section{Nursing Implications}

Environmental factors such as adequate time and clinic support are needed to enable nurses to communicate effectively and establish a useful rapport with patients which must be considered when exploring client reporting. 10 Proper attitudes, skills, and goals are required for the medical care provider to take an effective and comprehensive health assessment. 11 It has been observed by several colleagues (M. Morono, personal communication, October 16,1997 ) that clients are not being asked on the initial medical history and progress forms if they are currently using any type of alternative therapy. The NP or other medical care providers must ask the question about use of alternative therapies. The client's medical care may be improved with an awareness of any alternative therapies being used and their implications. NPs must also consider the perceived barriers when exploring a client's health promoting behaviors. Simply asking if a client is using an alternative therapy may be insufficient if there are perceived barriers. A client may be afraid to discuss the specifics of use for many reasons. It is also apparent that providers must evaluate their own attitudes regarding clients who use alternative therapies since clients still believe this to be a barrier to reporting. Providers failure to ask specific information 
regarding the extent of use of alternative therapies may represent a major deficit in current relationships between the client and medical provider. Future research is required to study how the attitudes of medical providers towards alternative therapies are perceived by clients and to what extent these attitudes effect client reporting. A recent survey by Tevelyan in 1996 demonstrated that $76 \%$ of 393 nurses surveyed stated they felt alternative therapies could improve the quality of life for their patients. 12 Also, further research to explore specific groups of clients who tend to use alternative therapies for the same reason they are seeking medical care is recommended. These groups have included clients with serious chronic illnesses such as cancer, and they could include clients with other auto-immune diseases such as clients with HIV, Scleroderma, Multiple Sclerosis, and other neuromuscular diseases. These clients could benefit from further research on the use of alternative therapies.

\section{Summary}

In this study, visiting both a medical provider and using an alternative therapy are considered health promoting behaviors. The reporting of alternative therapies by clients is viewed as a health promoting behavior by the medical care provider since the lack of reporting can have deleterious effects. This study found that two out of three participants surveyed $(68 \%, \underline{n}=34)$ used alternative therapies and only half of these clients $(56 \%, \underline{n}=18)$ reported their use to their medical providers. Also, the extent to which clients report their health behaviors in general may easily represent the rapport practitioners have with their clients. The answer to this quandrum is to simply ask questions regarding the utilization of alternative therapies just as if the medical provider were asking questions regarding the use of medications. Current research in the area of client reporting will hopefully enable the practitioner to begin to ask the 
right questions when exploring a client's health promoting behaviors. This study also demonstrated that participants who did not perceive barriers in reporting their use of alternative therapies to their medical care provider reported a larger percentage of specific information regarding their use of alternative therapies. How such attitudes affect client reporting requires a more thorough investigation with future research. 


\section{References}

1. Calkins, D. R., Delbanco, T. L., Eisenberg, D. M., Foster, L., Kessler, R. C., \& Norlock, F. E.: Unconventional medicine in the United States, prevalence, costs, and patterns of use. N Engl J Med. 1993; 328: 246-52.

2. Eisenberg, L., Good, B., \& Kleinman, A.: Culture illnesses and care: Clinical lessons from anthropologic cross-cultural research. 1978 Annals Int Med; $88,251-258$

3. Sutherland, L. R., \& Verhoef: Alternative medicine and general practitioners. Can Fam Phys 1995; 41: 1005-1010.

4. Weber, D. O.: The mainstreaming of alternative medicine. Health Care Forum-J 1996; 39(6) 16--27.

5. Slagle, M. W.: The nurse practitioner and issues of alternative therapies.

Nurs Practitioner: American J-Primary Health care 1996; 21(2) 16-18.

6. Laing, G. \& Montbriand: Alternative health care as a control strategy. J-Advanced Nurs 1991; 16: 325-332.

7. Cronsberry, T.: Alternative cancer therapies. Can-Nurse 1996; April (35-38).

8. Pender, N. Health Promotion in Nursing Practice (3rd ed.). New York: Appleton \& Lange, 1996.

9. Heathcote \& Wanless: Hepatotoxicity. Gastroenterologist 1995: 3(2) 119-129.

10. Fletcher, D. M. Unconventional cancer treatments: Professional, legal, and ethical issues. Oncology Nurs Forum 1992; 19, 1351-1354.

11. Naish, J: The route to effective nurse patient communication. Nurs Times 1996; 92(17) 27-30. 
12. Casey, L., \& Quirk, M.: Primary care for women: The art of interviewing.

J-Nurse Midwifery 1995; 40(2) 97-103.

13. Trevelyan, J.: A true compliment? Nurs Times 1996; 92(5) 42-43. 
Table 1

\section{Butterfield Alternative Therapies Survey Questions}

1. Are you currently using any of the following alternative therapies?

(a) Chiropractic, (b) Acupuncture, (c) Vitamins and / or Herbs

(d) Massage, (e) Energy Healing, (f) other.

2. If you answered yes to question \#1,

(a) Was the decision to use one or more of these therapies your own decision?

(b) Was the decision to use an alternative therapy by medical referral?

3. Are you currently undergoing medical care?

4. Are you going to a medical provider for the same reason you are using alternative therapies?

5. Have you revealed your use of alternative therapies to your medical provider?

(a) Were you asked the amount?___id you volunteer the amount? _

(b) Were you asked the frequency of use? _ Did you volunteer the frequency?

(c) Were you asked the number of visits or length of time concerning your use of an alternative therapy? _ Did you volunteer this information?

(d) Were you asked the type of herb, vitamin, mineral? _ Did you volunteer this information?

6. Were you ever asked the outcome or effectiveness of the alternative therapy you are using at any time while receiving medical care? Did you volunteer this information?

7. What percentage would you estimate you have revealed to your medical provider? $0 \%$ - $1 \%$ - $2 \%$ - $10 \%$ - $25 \%$ - $50 \%$ - $70 \%$ - $80 \%$ - $90 \%$ - $100 \%$ _

8. What prevented you from reporting or discussing your use of alternative therapies with your medical care provider? 


\section{Table 2}

Client's Use of Alternative Therapies While Receiving Medical Care Items $2,4,5$ and $6(\underline{N}=32)$

Survey Question
Responses (Frequency and Percent) Yes

$30(94 \%)$

$2(06 \%)$

$10(31 \%)$

4. Going to a medical provider for the same reason

5. Revealed use to medical provider

a. Provider asked amount

Client volunteered amount

b. Provider asked frequency

Client volunteered frequency

c. Provider asked length of time used

Client volunteered length of time use

d. Provider asked type of herb, vitamin, mineral

Client volunteered type of herb, vitamin, $\min$.

6. Provider asked outcome or effectiveness of tx. Client volunteered this information?
$18(56 \%)$

7 (22\%)

2 (06\%)

$8(25 \%)$

$1(03 \%)$

$4(12 \%)$

$0(0 \%)$

$9(28 \%)$

$2(06 \%)$

$8(25 \%)$

$3(09 \%)$
22 (69\%)

No

$2(06 \%)$

$30(94 \%)$

14 (44\%)

$23(72 \%)$

30 (93\%)

$23(72 \%)$

31 (97\%)

$28(88 \%)$

$0(0 \%)$

21 (66\%)

$30(94 \%)$ 


\section{Table 3}

Barriers to Reporting Use of Alternative Therapies to Medical Provider Item $8(\underline{N}=32)$

Response Category Frequency and Per Cent

No Perceived Barriers $11(34 \%)$

Client's Perception of Doctor's Opinion and Interest $10(32 \%)$

Client's Perception of Relevancy

$11(34 \%)$ 